CENSUS OF THE GALAXY: CHALLENGES FOR PHOTOMETRY AND SPECTROMETRY WITH GAIA 


\section{CENSUS OF THE GALAXY: CHALLENGES FOR PHOTOMETRY AND SPECTROMETRY WITH GAIA}

Proceedings of the Workshop held in Vilnius, Lithuania 2-6 July 2001

Edited by

VLADAS VANSEVIČIUS

Institute of Physics, Vilnius, Lithuania

ARŪNAS KUČINSKAS

Vilnius University Observatory, Vilnius, Lithuania

JOKŪBAS SŪDŽIUS

Vilnius University Observatory, Vilnius, Lithuania

Reprinted from Astrophysics and Space Science

Volume 280, Nos. 1-2, 2002

Springer-Science+Business Media, B.V. 
Library of Congress Cataloging-in-Publication Data

ISBN 978-94-010-3911-6 ISBN 978-94-010-0361-2 (eBook)

DOI 10.1007/978-94-010-0361-2

Cover illustration 'The Big Moon', $(50 \times 60 \mathrm{~cm}$, oil) by Zina Sviderskiene (private collection)

All Rights Reserved

(C) 2002 Springer Science+Business Media Dordrecht Originally published by Kluwer Academic Publishers in 2002

Softcover reprint of the hardcover 1st edition 2002

No part of the material protected by this copyright notice may be reproduced or utilized in any form or by any means, electronic or mechanical, including photocopying, recording or by any information storage and retrieval system, without written permission from the copyright owner. 


\section{TABLE OF CONTENTS}

Preface

Participants Photo

M.A.C. PERRYMAN / GAIA: An astrometric and photometric survey of our galaxy

\section{GAIA: PHOTOMETRY}

E. HØG / GAIA photometry: Selected topics

C.A.L. BAILER-JONES / Determination of stellar parameters with GAIA

V. VANSEVIČIUS, A. BRIDŽIUS and R. DRAZDYS / GAIA photometric system: Evaluation of performance

A. BRIDŽIUS and V. VANSEVIČIUS / GAIA photometric system: Simultaneous 4-D parameterization

V. DEVEIKIS, A. BRIDŽIUS and V. VANSEVIČIUS / GAIA photometric system: Simulation of photometric observations

C. FABRICIUS and L. LINDEGREN / The spectro point spread function for GAIA

A. KAZLAUSKAS, V. VANSEVIČIUS, A. BRIDŽIUS, R. DRAZDYS and R. KALYTIS / On the tolerances of filters for GAIA medium band photometric system

J. SÜDŽIUS and V. VANSEVIČIUS / Bandwidth effects in the $3 \mathrm{G}$ photometric system

J. KNUDE and N. KALTCHEVA / Transformations between Vilnius and Strömgren photometric systems

A. MIRONOV and A. ZAKHAROV / Systematic errors of high-precision photometric catalogues

M. FIORUCCI and U. MUNARI / The Asiago Database on Photometric Systems (ADPS) and the design of the GAIA photometric system

E. LASTENNET, T. LEJEUNE, E. OBLAK, P. WESTERA and R. BUSER / BaSeL: A library of synthetic spectra and colours for GAIA

N. GOUDA, T. TSUJIMOTO, Y. KOBAYASHI, T. NAKAJIMA, N. YASUDA and H. MATSUHARA / Japanese astrometry satellite mission for infrared exploration

\section{GAIA: ASTROPHYSICAL ISSUES}

J. KNUDE / Methods to account for interstellar extinction

J. SŪDŽIUS, S. RAUDELIŪNAS, A. KUČINSKAS, A. BRIDŽIUS and

V. VANSEVIČIUS / 3-D structure of the galactic interstellar matter: A contribution from GAIA

O. MALKOV and E. KILPIO / A synthetic map of the galactic interstellar extinction

A. KUČINSKAS and V. VANSEVIČIUS / Diffuse interstellar band at $862 \mathrm{~nm}$ as a reddening tracer for GAIA 
A. BARTKEVIČIUS and A. GUDAS / GAIA and population II visual binaries

O. MALKOV / Unresolved binaries and the initial mass function

V. DEVEIKIS, J. SPERAUSKAS and V. VANSEVIČIUS / Binary star detection with the GAIA radial velocity spectrometer

E. HØG / Detection of extra-solar planets by GAIA photometry

G. TAUTVAIŠIENÉ and B. EDVARDSSON / $\alpha$-Process elements in the galaxy: A possible GAIA contribution

A. KUČINSKAS, V. VANSEVIČIUS and T. TANABÉ / Asymptotic giant branch stars as tracers of star formation histories: the GAIA context

A. KUČINSKAS, A. BRIDŽIUS and V. VANSEVIČIUS / Globular clusters in the large magellanic cloud: An impact from GAIA photometry

G.A. TAMMANN and B. REINDL / GAIA and the extragalactic distance scale

\section{DISCUSSION}

C. FLYNN / Ground based testing of the GAIA filters

E. HØG / General discussion and photometric system for GAIA 


\section{PREFACE}

Astrometry from space was performed for the first time and with great success by the ESA Hipparcos satellite (1989-93). This mission was designed as an astrometry mission, but the use of a photon counting detector made it possible to produce very important photometric results: the most accurate astronomical photometry ever by the main Hipparcos mission in a very broad band of 120000 stars, and the two-colour Tycho-2 photometry of 2.5 million stars.

The cornerstone ESA mission GAIA was approved in October 2000 for launch not later than 2012. This mission will use CCDs in time-delayed integration mode instead of the photo-cathode detectors used in Hipparcos. Due to the higher quantum efficiency of the CCDs, simultaneous integration of many stars, and larger telescope apertures GAIA will utilize the star light a million times more efficiently than Hipparcos, resulting in astrometry and multi-colour photometry for one billion stars. GAIA photometry is crucial for the scientific utilization of the astrometric results, and the photometric data have a high scientific content in themselves.

The present Workshop is the first full-scale meeting of the GAIA Photometry Working Group. To hold the Workshop in Vilnius was natural in view of the many years of development and application of the Vilnius medium-band photometric system. The first photometric system proposed for GAIA some five years ago was a combination of the Vilnius and Strömgren systems. The Workshop was held on 2-6 July 2001 with 38 participants from 12 countries. The agenda covered the following broad subjects:

- Scientific and Technical Realization of the GAIA Mission;

- Classification and Design of the Photometric Systems;

- Methods and Data Bases for GAIA Testing;

- Astrophysical Issues.

There were 22 oral presentations, 15 posters, and a general discussion, most of which are represented in these Proceedings as refereed contributions.

We believe, that results presented in these Proceedings will provide a timely report on the current status in the design of the GAIA photometric instrument, providing also the recommendations for the future development of both groundand space-based photometry.

February 2002

Erik Høg and Vladas Vansevičius 
European Meeting

CENSUS OF THE GALAXY:

Challenges for Photometry and Spectrometry with GAIA

Vilnius, Lithuania 2-6 July 2001

\section{Scientific Organizing Committee:}

E. Høg (Denmark) and V. Vansevičius (Lithuania) - co-chairs,

C.A.L. Bailer-Jones (Germany), U. Bastian (Germany), C. Flynn (Finland), M. Grenon (Switzerland), C. Jordi (Spain), L. Lindegren (Sweden), M.A.C. Perryman (Netherlands)

\section{Local Organizing Committee:}

J. Sūdžius (chair), S. Bartašiūtè, A. Bridžius, R. Drazdys, R. Kalytis, A. Kazlauskas, A. Kučinskas, R. Lazauskaitè, V. Vansevičius

\section{SPONSORS}

- Department of Science and Higher Education under the Ministry of Education and Science of the Republic of Lithuania

- Lithuanian State Science and Studies Foundation

- Nordic Council of Ministers

- R\&G - precision optics

- Optida - precision optics

- Vilbrita - water filters

- BMK - computers and communications

- Lema - computers and communications

- Libra Vitalis - office equipment

- Rexnys Enterprises - science optics

- Kopra - office equipment

- Rašylas - office equipment

- Echo Stamp - office equipment

- Infostruktūra - information technologies 


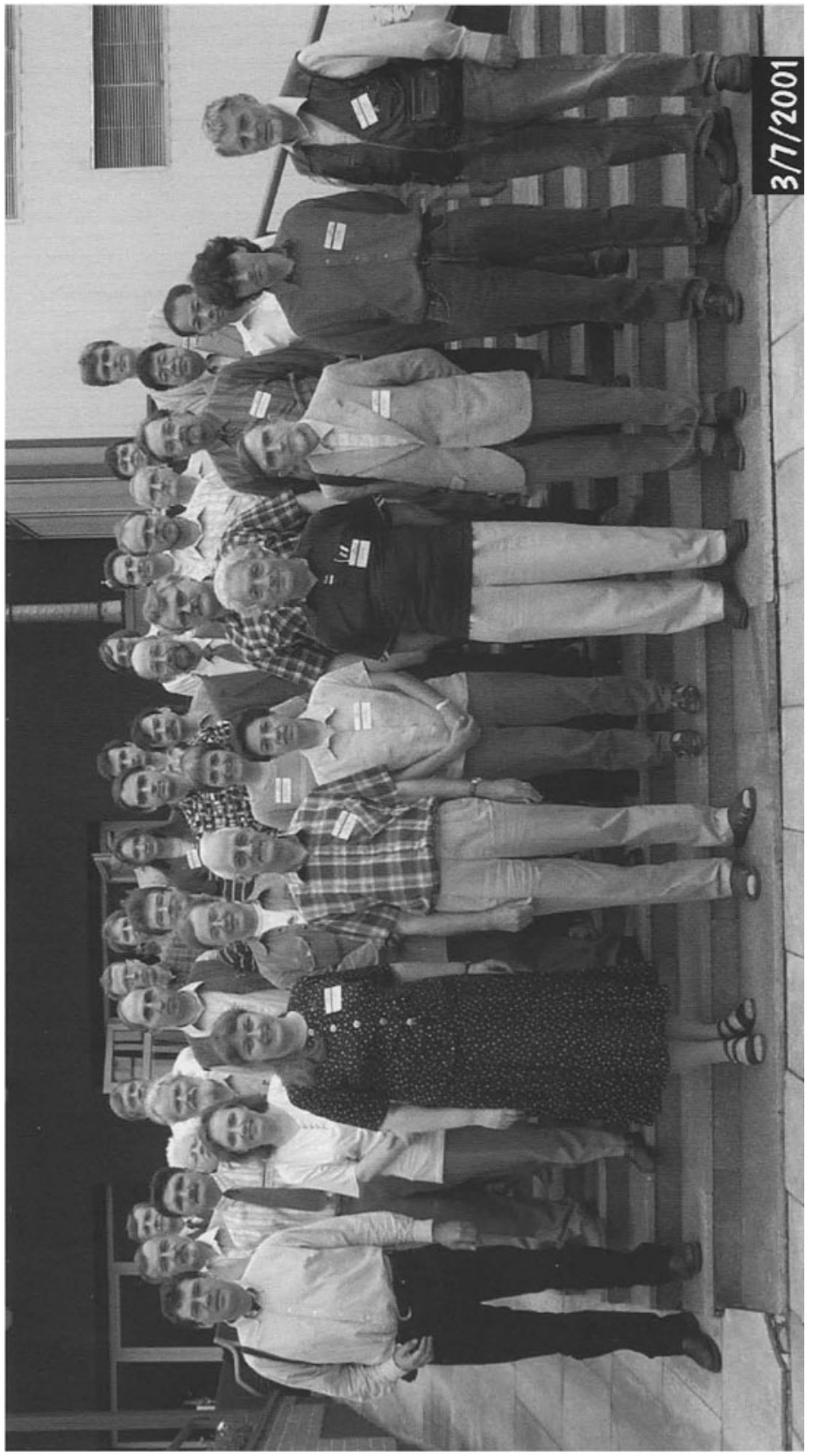

